\title{
Demographic Profile of Patients and Geospatial Mapping in Palliative Care: A Hospital Based Study from Eastern Part of India
}

Rita Rani ( $\square$ arunk31@gmail.com )

Mahavir Cancer Sansthan and Research Centre https://orcid.org/0000-0001-6730-5421

Usha Singh

Mahavir Cancer Sansthan and Research Centre

Vinita Trivedi

Mahavir Cancer Sansthan and Research Centre

Richa Chauhan

Mahavir Cancer Sansthan and Research Centre

Mukul Mishra

Mahavir Cancer Sansthan and Research Centre

Rajani Sinha

Mahavir Cancer Sansthan and Research Centre

\section{Research Article}

Keywords: Demographics, Geospatial mapping, Palliative Care, Cancer, Symptoms

Posted Date: May 17th, 2021

DOI: https://doi.org/10.21203/rs.3.rs-270799/v2

License: (1) This work is licensed under a Creative Commons Attribution 4.0 International License.

Read Full License 


\section{Abstract \\ Background}

With the rising burden of cancer in India, there is a huge need to start and expand Palliative care (PC) services in different parts of the country. understanding the demographic profile of the Palliative care patients will help in customising the PC services. Aim of the study was to look into demographic details of the patients and to do Geospatial mapping of the patients referred for PC.

\section{Methods}

Data was extracted from patient's case records referred to PC OPD was put into Excel sheet analysed statistically along with Geospatial mapping.

\section{Results}

Among a total of 1084 patients, $54.9 \%$ were men and about $24.2 \%$ were women. Maximum number of patients were in 4 th decade of their life, relatively younger population. About $57 \%$ were poor and $47.1 \%$ were illiterate. About $37.2 \%$ were head and neck cancer patients with pain as the most commonly reported symptom among all patients. Bony metastasis was most common and majority of the patients belonged to Patna District of Bihar.

\section{Conclusions}

This study of demographic patterns of patient and geospatial mapping will help in sensitising towards PC and establishing better PC services and policy making in different parts of the country.

\section{Introduction}

Cancer has huge impact on social and economic conditions for people in India especially due to late stages of presentation of disease. It is a major cause of morbidity and mortality in developing countries. In India the incidence of cancer is rising. [1] The estimated incidence of cancer in 2015 was 1,148,691 which may be $1,320,928$ cases in 2020. [2] More than $80 \%$ of the cases present in advanced stages where even after curative intent, patients need for PC becomes absolute essential. [3] As cancers are detected in late stages in India, it is estimated that more than one million people will need Palliative Care (PC). [4]

Palliative care (PC) is a specialised health care offered to the patients dealing with chronic, debilitating, lifethreatening illness from diagnosis till death to bereavement. According to World Health Organisation (WHO) palliative care is defined as "an approach that improves the quality of life of patients and their families facing the problems associated with lifethreatening illness, through the prevention and relief of 
suffering by means of early identification, impeccable assessment and treatment of pain and other problems, physical, psychosocial, and spiritual”. [5]

However, the awareness of Palliative care needs of patients is lacking in most parts of the country except

the state of Kerala. There are around 380 centres for PC in India, out of which 214 are in Kerala, a small state, and there are only 4 in a large state like Uttar Pradesh. [6]

In the state of Bihar, the third most populous state of India only a handful of patients have access to Palliative care and at very few centres. In this study, the first of its kind, we are going to analyse the patient's demographic profile who were referred to PC out patient department (OPD) in our cancer hospital. This kind of study is lacking in eastern part of India, which might help in setting up of PC services in new places. Knowing about the kind of patients in need of PC is of prime importance to customize the needs of the PC services.

\section{Materials And Methods}

This study was conducted in Mahavir Cancer Sansthan and Research Centre, situated in the capital city of Bihar, Patna. All patients who were referred to PC out patient department (OPD), in the first 2 years of starting the OPD on 14th March, 2018, there case records were studied in details regarding patients demographic details and their needs. Geospatial mapping was also carried out for all the studied patients using MS Excel 2019 software. Ethical approval was obtained from Institutional Ethics Committee of our Institute before the start of the study. Total number of patients were 1084. Data was collected and statistical analysis was done with ANOVA test.

\section{Results}

1. Gender wise distribution: A total of 1084 patients were seen over a period of 2 years. $9 \%$ of patients were men and $45.1 \%$ women respectively (Fig. 1).

2. Age wise distribution: The data was sorted according to age distribution. Maximum patients who required palliative care were in the age group of 41 to 50 years (Fig.2.) $57 \%, 42.8 \%, 0.09 \%$ of the patients were of low, middle and high socioeconomic status respectively . $47.1 \%$ of patients were illiterate while $17.9 \%, 12 \%, 22.7 \%$ had primary, middle and higher education respectively.

3. Diagnosis of the palliative cancer patients: The leading site of cancer patients who required palliative care were head neck cancer followed by breast and pelvic cancer patients (Fig. 3).

4. Diagnosis - various metastatic sites: A total of $7 \%$ of patients had metastatic disease at the time of referral to PC OPD.14.4\% of patients had metastsis at multiple sites. The commonest site of metastasis was bone followed by liver, lungs and brain (Fig. 4).

5. Leading Symptoms of palliative care patients: Majority of the patients had more than one symptom.Pain was the most distressing symptom followed by weakness, fungating ulcer,anorexia and swelling (Fig.5.). Other notable symptoms were dysphagia, bleeding,constipation, nausea , 
vomitting, diarrhoea, sleeplessness, cough and breathlessness. $7 \%$ of the patients had pain which ranged from mild to severe pain. $52.6 \%$ patients needed strong opioids while $37.7 \%$ patients needed weak opoids to control pain.

6. Geospatial distibution of Pallative care patients: Geospatial mapping of the cancer cases in Bihar was plotted (Fig.6) and it was observed that patients came from all districts of Bihar, far and near with $7.3 \%$ of patients coming outside the state. Maximum number of patients came from Patna district followed by Muzaffarpur and Samastipur.

\section{Discussion}

Having analysed the data of patients of palliative care, it was observed that the referral for palliative care in our set up was low. Going by our hospital registry, only $2.74 \%$ of patients were referred for PC. stages of However, more than 2/3rd of the patients presents in advanced cancer and need PC in the trajectory of incurable disease. Oncologists endeavour to treat patients until all cancer directed treatments fail ends up referring the patients for PC in which it is mainly "end of life" care. However, early introduction of PC has shown to improve quality and quantity of life. [7] The early PC has been shown to influence patientrelated outcomes also. [8]

Going by age distribution maximum number of patients (24.2\%) were in the age group of 41 to 50 years required PC services. This was relatively younger population. Study from Cipla Palliative care centre, which lies in the western part of India shows that the peak age of patients requiring palliative care were between age of 51 to 60 years. [9]

In India, the need for PC is high, but will be guided by socioeconomic conditions of the country. [10] Approximately $57 \%$ of the who came for PC in our study were of low socioeconomic status and needed financial help to support their treatment cost. Similar study from other part of India by Rajmohan and Kumar showed a $82 \%$ of patients needing PC were of low socioeconomic status.[11]

Low levels of education are prevalent among patients needing palliative care. In our study a high proportion of patients, that is, $47.1 \%$ were illiterate and $17.9 \%$ had their education level till primary school only. A similar study from New Delhi, Capital city of India also had 21\% illiterates in need of PC.[12]

In this study, maximum number of patients needing PC were head neck cancer patients which is the number one cancer among males in our hospital. According to a multi-institutional study also $65 \%$ of new head and neck cancers with locally advanced disease did not benefit from optimal treatment, resulting in poor survival. [13] The second most leading cancer were breast cancer patients in need of PC which is the most common cancer in women of our hospital. This is in sync with GLOBOCAN 2018 data for India where number of new cases of five most common cancers are Breast cancer $(14 \%)$, followed by cancer of lip (10.4\%), cervix uteri (8.4\%), lung (5.9\%) and stomach (5\%).

Approximately $70 \%$ bony metastasis occur in cases of Prostate and breast cancer. [14] Bone is the third most common site of metastasis, after lung and liver.[15] However, in our study the maximum number of 
patients presented with bony metastasis, followed by liver, lung and brain. This difference in data could be because maximum number of patients who were referred to PC were for pain management. This could also be due to fact that maximum number of patients referred for PC were from Radiotherapy department.

In our study leading symptom of patients in PC was pain (97.4\%). The prevalence of pain has been $90-$ $100 \%$ among patients in two of the PC OPD clinics in other parts of the country. $[16,17]$ Cancer pain is perhaps the most feared symptom associated with cancer. Pain is subjective in nature, is difficult to quantify and may vary in intensity. This pain could be due to malignancy itself or due to soft tissue infiltration, nerve compression and bony metastasis. According to Clohysi et al, the most common cause of pain is bony pain in cancer, which is poorly localized, gets worse at night and remains unrelieved by sleep or lying down. [18] About 52.6\% patients of needed strong opioids and $37.7 \%$ needed weak opioids to control pain. Opioids play important role in treatment of moderate to severe pain because of their rapid effectiveness [19], lack of ceiling effect, and no direct detrimental effects on organ functions.

Geo spatial mapping was done to have an idea from where the patients came. Majority of the patients came from Patna district followed by Muzaffarpur and Samastipur. Patients came from all districts of Bihar, however availability of PC services is in 2 districts only, that also in few of hospitals amongst 38 districts of Bihar. There is a huge gap of access to PC in our state. It is clear that local problems require local solutions. Considering the size of population which requires PC, manyfold efforts have to be made. The state of Kerala has certainly set an example.[20] The other places in country should try to learn from Kerala, not necessarily use the same model but at least try emulating the spread.[21]

Palliative care is an emerging discipline in India and still faces many challenges that have to be overcome.[22] Our study also shows in spite of PC OPD on our Institute, referral of the patients is poor. To sum up a lot needs to be done in this part of the country to build up a structured way of delivering PC starting from raising awareness amongst health care professionals and general public to availability of opioids in every district of Bihar and in the country.

\section{Conclusion}

The study of demographic profile of patients will help in understanding the profile of patients in need of PC services in our part of the country. It will also guide appropriate support for action to strengthen efforts to customise and improvise PC services. This will also help in sensitizing health care workers to integrate and introduce PC services earlier in the trajectories of the disease. Hopefully it will help in strengthening and expanding PC services for more and more people in need in different districts of Bihar. Continued efforts are needed to overcome the barriers for successful implementation of PC services in our part of country.

\section{Abbreviations}


PC: Palliative Care; WHO: World Health Organisation; OPD: outpatient department

\section{Declarations}

\section{Ethics Approval and consent to Participate}

All the authors confirm that all the methods were carried out in accordance with the relevant guidelines and regulations. All the experimental protocols were approved by Mahavir Cancer Sansthan and Research Centre's Institutional Ethics Committee. Furthermore, the informed consent was obtained from all the patients and from the parents or legal guardians for the patient under 18 years of age.

\section{Consent for Publication}

Not applicable

\section{Funding}

Not applicable

\section{Authors' contributions}

The research work was conceptualized by R.R. Data were analysed by R.R., V.T., RC, US, MM and RS. The first draft of the manuscript was written by RR. All authors gave the final approval and agreed to be accountable for all aspects of work ensuring integrity and accuracy.

\section{Conflict of interests}

The authors declare that they have no conflict of interests.

\section{Availability of data and materials}

The datasets used and analyzed in the current study are available from the corresponding author on reasonable request.

\section{Acknowledgements}

We thank Dr. Arun Kumar, Senior Scientist, Research Centre (MCSRC) for statistical analysis of the data. We also thank our medical social worker, Miss Priyanka Gupta for collecting the data.

\section{References}

1. Goss PE, Strasser-Weippl K, Lee-Bychkovsky BL, Fan L, Li J, Chavarri-Guerra Y, et al. Challenges to effective cancer control in China, India, and Russia. Lancet Oncol 2014;15:489-538.

2. Central Bureau of Health Intelligence. Projected Cases of Cancer at India Level for Selected Times and Selected Time Periods. Available from: 
http://www.cbhidghs.nic.in/writereaddata/mainlinkFile/NHP-2015.pdf. [Last accessed 2017 Aug 07]

3. Cancer control: Knoweledge into Action: WHO Guide for Effective Programmes [Internet]. Geneva: World Health Organization; 2008. Available from: http:// www. who.int/cancer/modules/FINAL_ Module_4.pdf .[Last cited 2013 Nov 17].

4. World Health Organization and World-Wide Palliative Care Alliance (WPCA); Global Atlas of Palliative Care at End of Life. Available from: http://www.who.int/nmh/Global_Atlas_of_Palliative_Care. [Last accessed on $2018 \mathrm{Jul} 30]$.

5. Geneva: World Health Organization. World Health Organization Definition of Palliative Care. Available from: http://www.who.int/ cancer/palliative/definition/en. [Last accessed on $2018 \mathrm{Jul}$ 28].

6. Pallium India. Directory of Palliative Care Services. Available from: http://www.palliumindia.org/resources/clinics/. [Last accessed 2017 Aug 07].

7. Dahlin CM, Kelley JM, Jackson VA, Temel JS. Early palliative care for lung cancer: Improving quality of life and increasing survival. Int J Palliat Nurs 2010;16:420-3.

8. Salins N, Ramanjulu R, Patra L, Deodhar J, Muckaden MA. Integration of early specialist palliative care in cancer care and patient related outcomes: A critical review of evidence. Indian J Palliat Care 2016;22:252-7.

9. John P, Ghooi R. Profile of Patients Opting for Palliative Care in India. Indian journal of Palliative Care 2017; IP: 123.252.238.194

10. Lal M, Raheja S, Kale S, Bhowmik KT. Palliative care tailored towards the needs of the poor in India. Indian J Surg Oncol 2015;6:227-31.

11. Rajmohan V, Kumar SK. Psychiatric morbidity, pain perception, and functional status of chronic pain patients in palliative care. Indian J Palliat Care 2013;19:146-51

12. Singh DP. Quality of life in cancer patients receiving palliative care. Indian J Palliat Care 2010;16:3643

13. Nandakumar A, Kishor Rath G , Chandra Kataki A, et al : Survival in head and neck cancers: Results of a multi-institution study. Asian Pac J Cancer Prev 17 : 1745 - 1754, 2016.

14. Cecchini M, Wetterwald A, Pluijm G, Thalmann G. Molecular and biological mechanisms of bone metastasis. EAU Update Series 2005; 3:214-26.

15. Coleman R. Metastatic bone disease: clinical features, pathophysiology and treatment strategies. Cancer Treat Rev 2001; 27:165-76.

16. Suresh Kumar R, RajaGopal MR. Palliative Care in Kerala. Problems at presentation in presentation in 440 patients with advanced cancer in South Indian state. Palliat Med 1996; 10:293-8.

17. Sebastian $P$, Varghese $C$, Sankarnarayanan $R$ et al. Evaluation of symptomology in planning palliative care. Pall Med 1993; 7:27-34.

18. Clohisy D, Mantyh P. Bone cancer pain. Cancer2003; 97:866.

19. Wiffen PJ, Wee B, Derry S, et al. Opioids for cancer pain - an overview of Cochrane reviews. Cochrane Database Syst Rev. 2017;7:CD012592 
20. Bollini P, Venkateswaran C, Sureshkumar K. Palliative care in Kerala, India: A model for resource-poor settings. Onkologie 2004;27:138-42.

21. Kumar S. Models of delivering palliative and end-of-life care in India. Curr Opin Support Palliat Care 2013;7:216-22.

22. Rajagopal MR, Venkateswaran C. Palliative care in India: Successes and limitations. J Pain Palliat Care Pharmacother 2003;17:121-8.

\section{Figures}

\section{Gender Wise Palliative Care Patients $(n=1084)$}

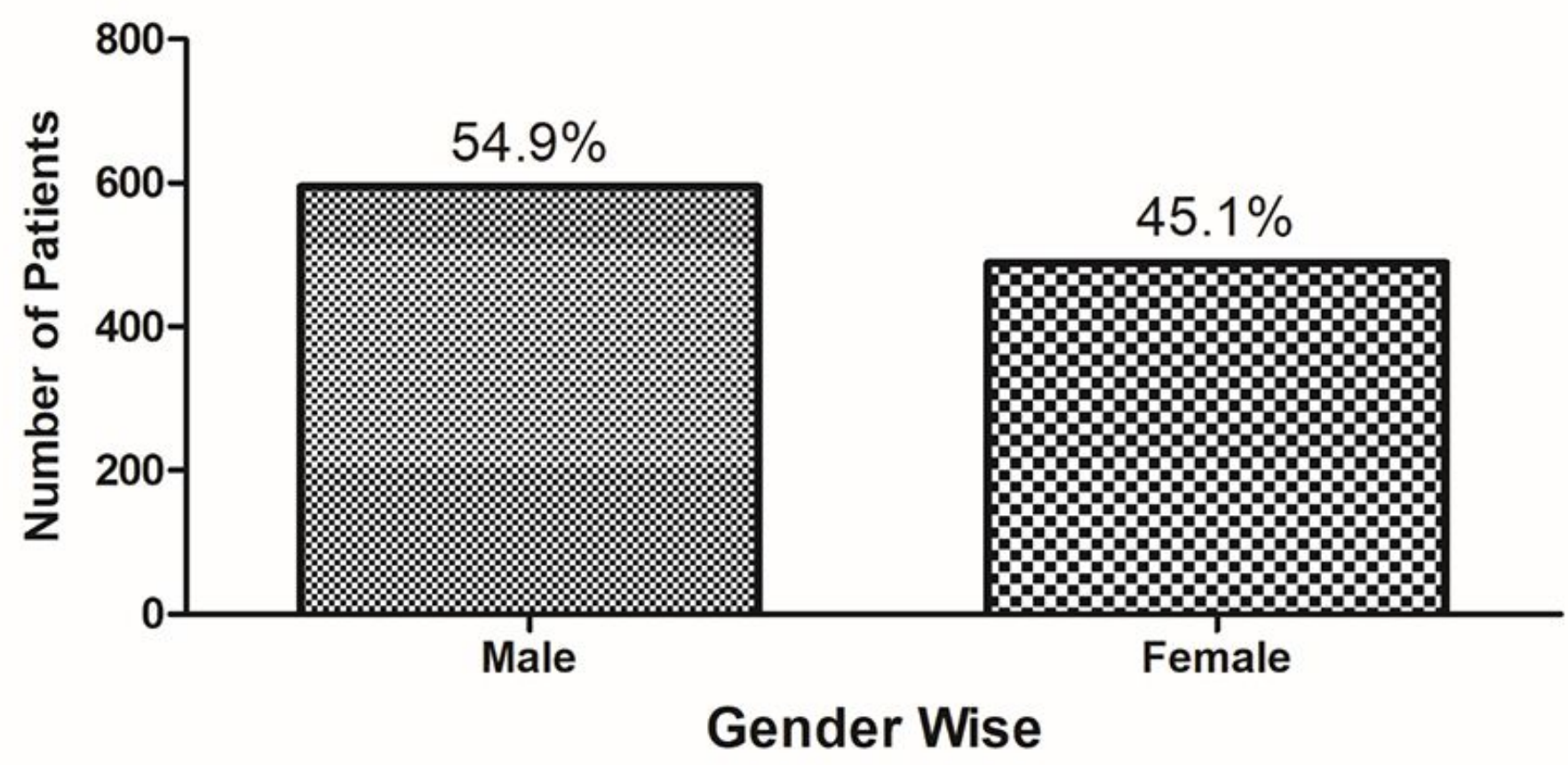

Figure 1

Gender wise distribution of palliative care patients. (ANOVA-Dunnett's Test, $\mathrm{P}<0.05$ ). 


\section{Age Wise Palliative Care Patients $(n=1084)$}

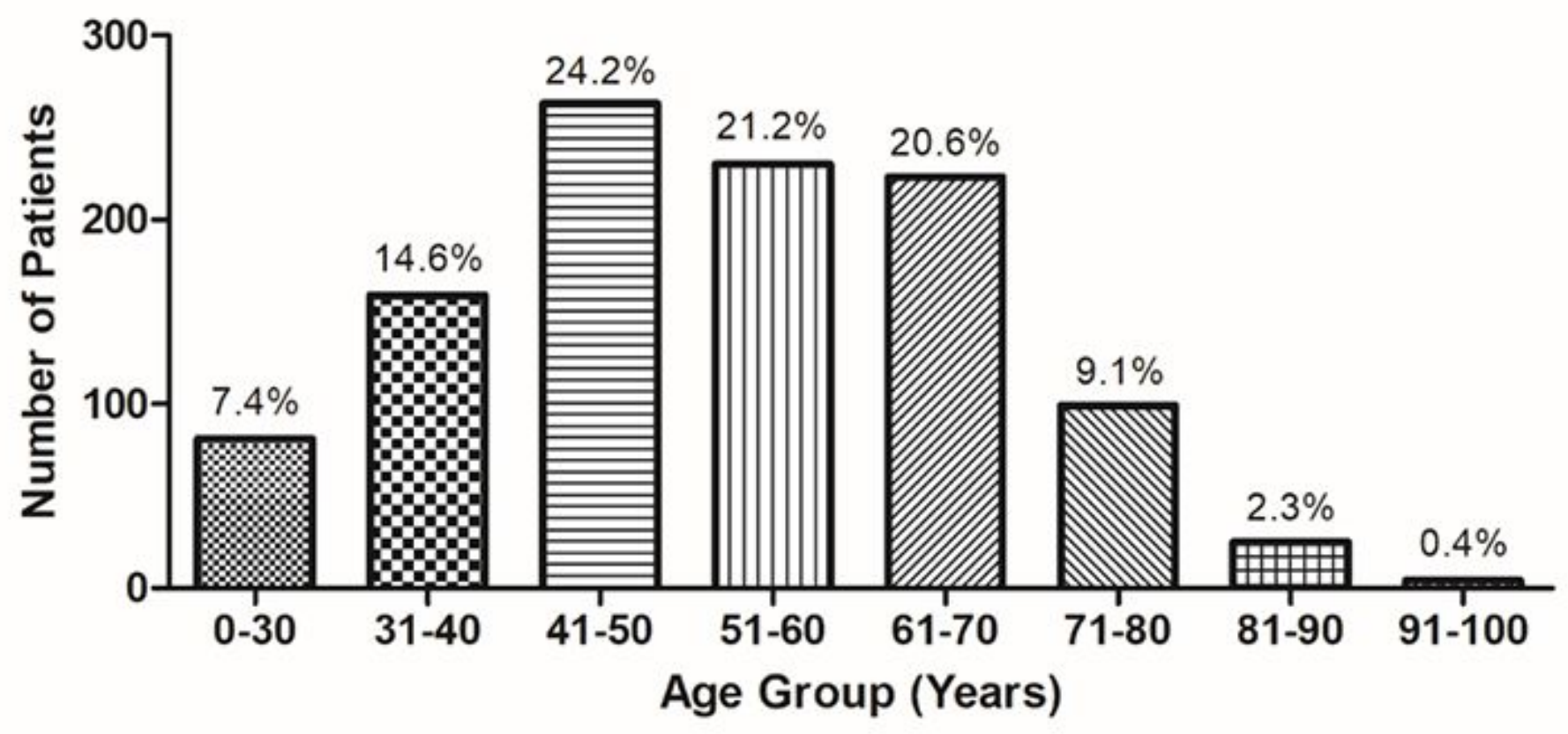

Figure 2

Age wise distribution of Palliative care patients. (ANOVA-Dunnett's Test, $\mathrm{P}<0.05$ ).

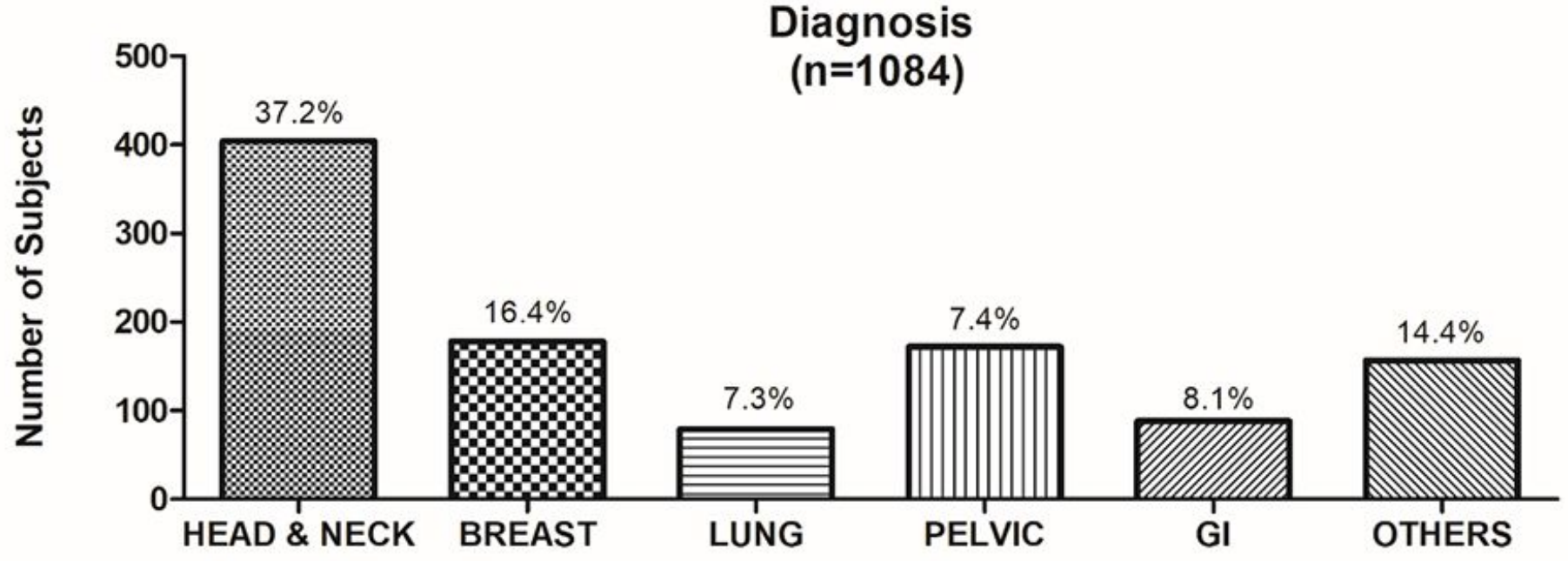

Figure 3

Diagnosis wise distribution of the cancer patients. (ANOVA-Dunnett's Test, $\mathrm{P}<0.05$ ). 


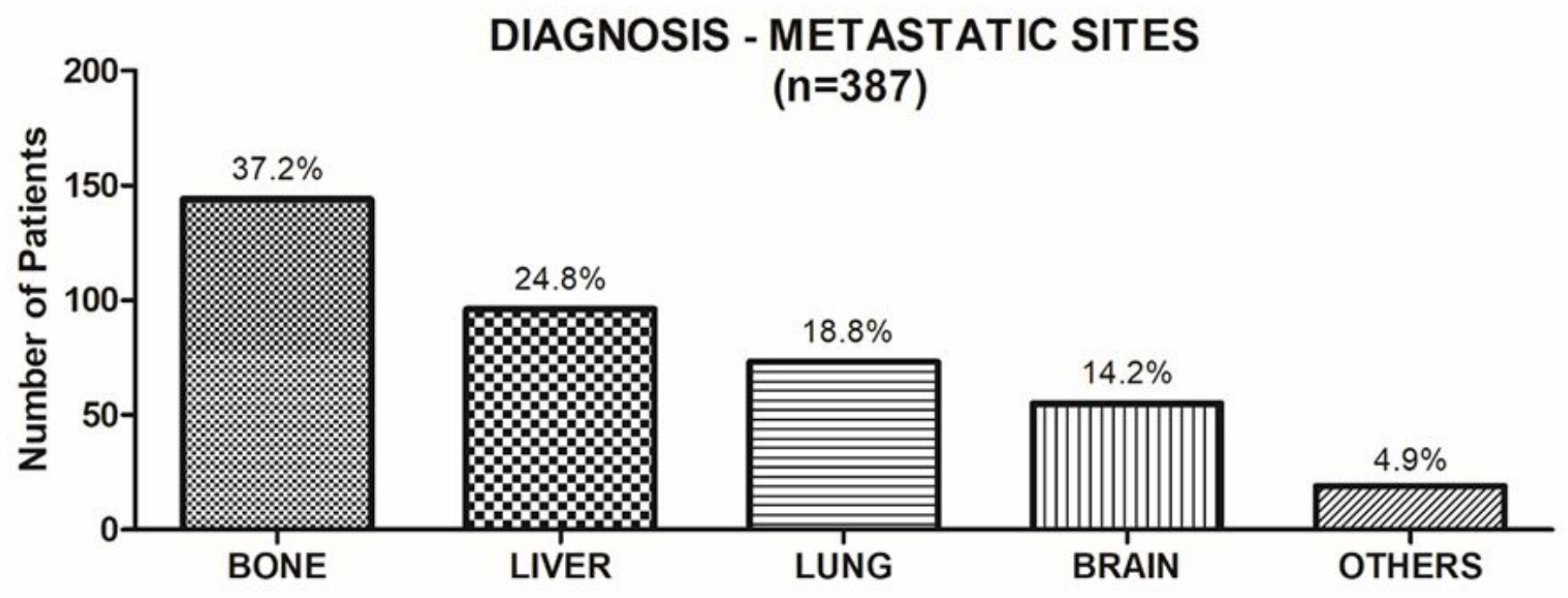

Figure 4

Diagnosis - various metastatic sites. (ANOVA-Dunnett's Test, $\mathrm{P}<0.05$ ).

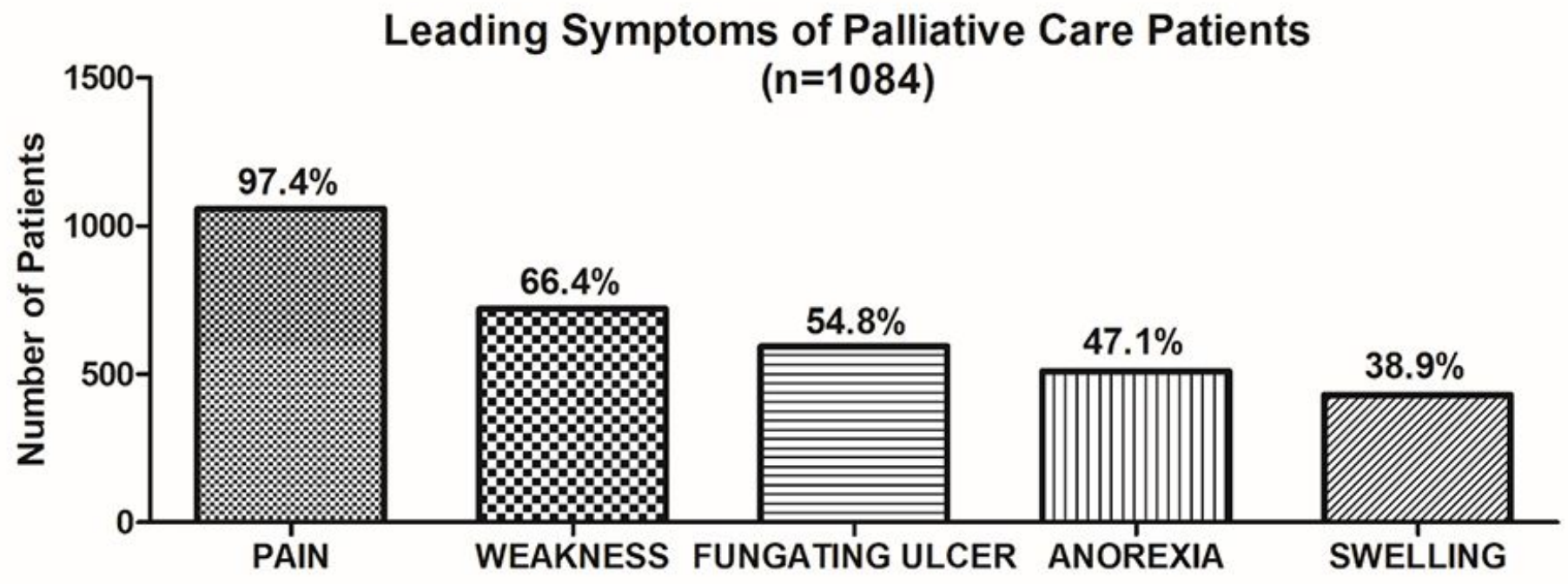

Figure 5

Leading Symptoms of palliative care patients. (ANOVA-Dunnett's Test, $\mathrm{P}<0.05$ ). 


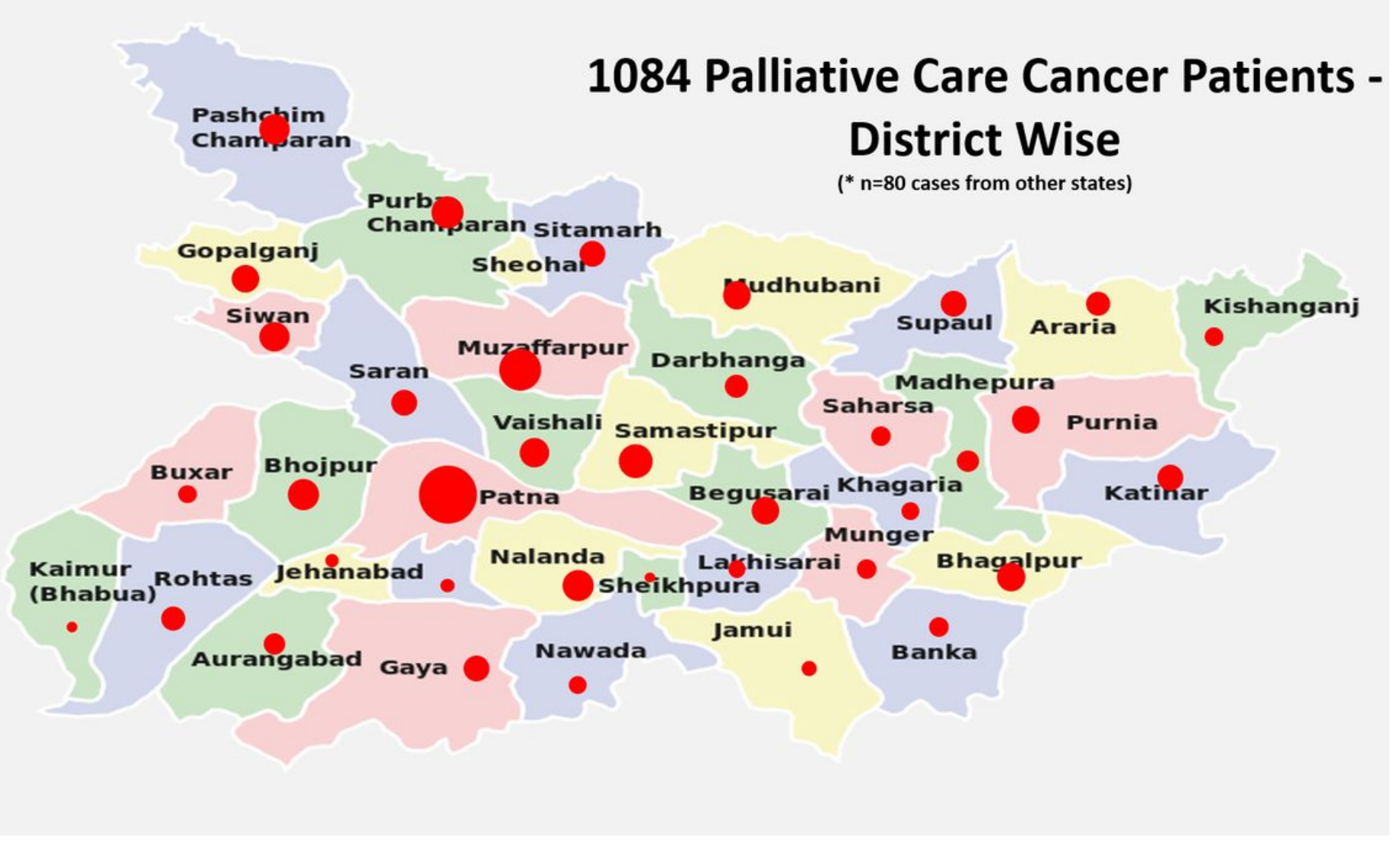

Figure 6

Geospatial distribution of cancer patients. Note: The designations employed and the presentation of the material on this map do not imply the expression of any opinion whatsoever on the part of Research Square concerning the legal status of any country, territory, city or area or of its authorities, or concerning the delimitation of its frontiers or boundaries. This map has been provided by the authors. 